\title{
Poor perception of dyspnoea in children with undiagnosed asthma
}

\author{
R. van Gent*, L.E.M. van Essen-Zandvliet" ${ }^{\#}$ M.M. Rovers ${ }^{\uparrow,+}$, J.L.L. Kimpen ${ }^{\S}$, \\ G. de Meer ${ }^{f * *}$ and C.K. van der Ent ${ }^{\# \#}$
}

ABSTRACT: The aim of the present study was to establish the differences in dyspnoea perception between children with undiagnosed and diagnosed asthma.

A cross-sectional community-based study was performed, which included a parental questionnaire on the child's respiratory health and testing of airway reversibility and bronchial hyperresponsiveness (BHR). "Diagnosed asthma" was defined by a physician's diagnosis of asthma. "Undiagnosed asthma" was defined by the presence of asthma symptoms combined with either airway reversibility or BHR without a physician's diagnosis of asthma. Only children with a positive BHR test were selected for further analysis. Perception of dyspnoea was assessed using the Borg scale and the visual analogue scale (VAS), plotted against the percentage fall in forced expiratory volume in one second and expressed as the slope of the regression line.

Of the initial 1,758 participating children, 70 had undiagnosed asthma and 38 had diagnosed asthma. The Borg and VAS slopes in children with undiagnosed asthma were less steep than those of children with diagnosed asthma (Borg: 0.07 and 0.14, respectively; VAS: 0.06 and 0.11 , respectively).

Among children with bronchial hyperresponsiveness, those without a parent's report of physician's diagnosis of asthma had a worse perception of dyspnoea than children with diagnosed asthma.

KEYWORDS: Asthma, children, dyspnoea, perception

I $\mathrm{n}$ Western European and affluent countries, asthma is the most common chronic disease with up to $32 \%$ prevalence in childhood $[1,2]$. Patients with asthma vary greatly in their ability to perceive spontaneous and acutely induced bronchoconstriction [3, 4]. JuLIUS et al. [5] showed that children with life-threatening asthma were poor perceivers of dyspnoea during bronchoprovocation. Furthermore, a substantial proportion of children with asthma underestimate their bronchoconstriction, as measured by symptom scores, obstruction scores or breathing perception [6].

In recent decades it has been suggested that asthma in children is underdiagnosed and, subsequently, under-treated [7]. Recent data show that underdiagnosis is still a problem. For example, JOSEPH et al. [8] reported an $11.7 \%$ prevalence of undiagnosed asthma.

Although poor perception of dyspnoea seems to play a role in severe asthma, it is unclear whether poor perception is also a cause of under-recognition of asthma symptoms in the general population [9]. To date, no information is available on perception of dyspnoea in children with undiagnosed asthma.
Therefore, the present study explored whether perception of dyspnoea differs between children with undiagnosed and diagnosed asthma. To address this question, the perception of dyspnoea was evaluated during a bronchial hyperresponsiveness (BHR) test in children aged 7-10 yrs with both undiagnosed and diagnosed asthma from an unselected population cohort.

\section{METHODS}

\section{Population and study protocol}

The study was conducted at the Máxima Medical Center (Veldhoven, the Netherlands) in 41 out of 44 primary schools in four cities in the south of the Netherlands. All children aged 7-10 yrs (groups 5 and 6) and their parents were asked to participate in the present study. All participating children were invited for lung function testing with assessment of reversibility after administration of salbutamol. Bronchial challenge testing was performed in all children with asthma symptoms, irrespective of a physician's diagnosis of asthma. A child was considered to have asthma symptoms if he/she had wheeze or dry cough in the previous 12 months. For the present study, a child was considered to have

\section{AFFILIATIONS}

*Dept of Paediatrics, Máxima

Medical Center, Veldhoven,

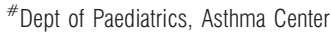

Heideheuvel, Hilversum,

${ }^{* *}$ Dept of Health Sciences,

University Medical Center Groningen, University of Groningen, Groningen,

"Julius Center for Health Sciences

and Primary Care,

Depts of Paediatrics,

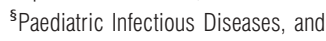

\#\#Paediatric Pulmonology,

University Medical Center Utrecht, and

fInstitute for Risk Assessment Sciences (IRAS), Utrecht University, Utrecht, The Netherlands.

CORRESPONDENCE

R. van Gent

Dept of Paediatrics

Máxima Medical Center

P.0. Box 7777

$5500 \mathrm{MB}$

Veldhoven

The Netherlands

Fax: 31408888273

E-mail: R.vanGent@mmc.nl

Received:

March 152007

Accepted after revision:

July 122007

STATEMENT OF INTEREST

A statement of interest for J.L.L. Kimpen can be found at

www.erj.ersjournals.com/misc/ statements.shtml

European Respiratory Journal Print ISSN 0903-1936 Online ISSN 1399-3003 
current "diagnosed asthma" if the parents confirmed that the child had current complaints and physician-diagnosed asthma in the previous 12 months. A child was considered to have "undiagnosed asthma" if the child had: 1) no parent report of physician-diagnosed asthma in the previous 12 months; 2) asthma symptoms (wheeze or dry cough) in the previous 12 months; and 3) either reversible airway obstruction or BHR.

Approval for the study was obtained from the Central Committee on Research involving Human Subjects (the Hague, the Netherlands), from the hospital ethics committee and from the principals of the schools involved. Informed written consent was obtained from the parents of all children.

\section{Lung function testing}

Maximal flow-volume curves were measured using a handheld spirometer (Vitalograph Ltd, Maids Moreton, UK) according to European Respiratory Society guidelines [10]. Airway reversibility was defined as an increase in forced expiratory volume in one second (FEV1) $\geqslant 10 \%$ of the predicted value $10 \mathrm{~min}$ after administration of $800 \mu \mathrm{g}$ salbutamol using a Volumatic ${ }^{\circledR}$ spacer (GlaxoSmithKline, Uxbridge, UK) [11].

\section{Hypertonic saline testing}

BHR was assessed by an inhalation challenge with nebulised hypertonic $(4.5 \%)$ saline using an ultrasound nebuliser (Klava 2000/4000; Klava Eltromed, Bielefeld, Germany) according to the International Study of Asthma and Allergies in Childhood (ISAAC) protocol [12]. All children were asked to withhold all asthma medications for $\geqslant 12 \mathrm{~h}$ beforehand. Children with a baseline FEV1 $\leqslant 75 \%$ pred were excluded. Children with a respiratory tract infection $\leqslant 4$ weeks before the BHR test received a new appointment. Children inhaled the saline for periods of increasing duration: $0.5,1,2,4$ and $8 \mathrm{~min}$. FEV1 was measured $1 \mathrm{~min}$ after each inhalation period and the next inhalation period started after $3 \mathrm{~min}$. Bronchial challenge was stopped if FEV1 had fallen $\geqslant 15 \%$ from the baseline value or if the total inhalation period of $15.5 \mathrm{~min}$ had been completed. A child was defined as having BHR if FEV1 had dropped $\geqslant 15 \%$ from baseline during the inhalation challenge. The provocative dose of hypertonic saline causing a $15 \%$ fall in FEV1 was calculated by linear interpolation between the last two points in the dose-response curves [13].

\section{Assessment of perception of dyspnoea}

The severity of dyspnoea during the challenge test was assessed by a Borg scale and a visual analogue scale (VAS) [14]. After each dose step children were asked: "How severe is your breathlessness during and directly after this inhalation?" The Borg scale consists of vertically labelled categories ranging $0-10$, i.e. no dyspnoea to maximal dyspnoea. The VAS scale is a horizontal line $(100 \mathrm{~mm})$ labelled "no breathlessness at all" at one end $(0 \mathrm{~mm})$ and "most extreme breathlessness ever experienced" at the other $(100 \mathrm{~mm})$, whereby equal distances represent equal increments in the severity of breathlessness. During the tests, subjects were blinded to their lung function response.

\section{Questionnaire}

Parents completed a questionnaire that included the ISAAC core questions on symptoms of asthma, rhinitis and eczema.
The questionnaire used has been reported elsewhere [15]. Additional data were collected on household characteristics, such as parental education, passive smoking and pet ownership. Asthma symptoms were defined as wheeze or a dry cough at night in the previous 12 months.

\section{Statistical analysis}

Chi-squared and unpaired t-tests were used to test whether the demographic, patient and clinical characteristics differed between children with diagnosed and undiagnosed asthma. Only children with a positive BHR test were selected for further analysis. Borg and VAS scores were plotted against percentage decrease in FEV1 from baseline. These individual Borg/FEV1 and VAS/FEV1 slopes are known to represent an index of dyspnoea, i.e. each slope indicates the perception of airway obstruction: the steeper the slope the more sensitive the subject is to signals of bronchoconstriction [16]. The intercepts represent baseline Borg and VAS scores. Differences between the slopes and the corresponding intercepts were analysed by the Mann-Whitney U-test.

\section{RESULTS}

\section{Participants}

Of 44 eligible schools, 41 participated in the study. Reasons for nonparticipation were recent involvement in another study $(n=2)$ and a school policy never to participate in medical studies $(n=1)$. The parents of all 2,745 children were invited to participate in the study from September 2002 to April 2005. Of these, 1,758 (64\%) parents gave informed consent to participate. A total of 144 children were excluded from further analysis due to missing questionnaire data $(n=60)$ or refusal to participate in bronchial challenge testing $(n=31)$. Additionally, 53 children were excluded from data analysis as they were unable to complete the bronchial challenge test due to nausea or coughing $(n=3)$, or were unable to meet technical conditions $(n=50)$.

\section{Diagnosis and demographics}

The study population comprised 1,614 children, of whom 130 $(8 \%)$ had undiagnosed asthma and $81(5 \%)$ had diagnosed asthma according to the present authors' criteria. Of these, 99 children had a positive BHR test: 70 children with undiagnosed asthma and 29 with diagnosed asthma. Table 1 presents the characteristics of the final study population. No differences were found between children with undiagnosed and diagnosed asthma with respect to age, parents with asthma and currently smoking parents. Demographic data of children with (un)diagnosed asthma without BHR did not differ from the demographic data in the group of children with diagnosed or undiagnosed asthma with a positive BHR (data not shown).

Table 2 presents the questionnaire and lung function data. Children with diagnosed asthma had more wheezing symptoms and less change in FEV1 at the end of the BHR test than children with undiagnosed asthma. All children with a parent's report of asthma reported asthma symptoms (wheeze or dry cough at night) in the previous 12 months.

Figure 1 presents a representative example of the relationship between the Borg score and FEV1. Each slope indicates the perception of airway obstruction of an individual patient: the steeper the slope the more sensitive the subject is to signals of 


\begin{tabular}{|c|c|c|}
\hline & Undiagnosed asthma & Diagnosed asthma \\
\hline Subjects $n$ & 70 & 29 \\
\hline \multicolumn{3}{|l|}{ Sex } \\
\hline Male & $30(43)$ & $19(66)$ \\
\hline Female & $40(57)$ & $10(35)$ \\
\hline Age yrs & $9.3 \pm 0.8$ & $9.4 \pm 0.8$ \\
\hline Mother asthma ever & $10(17)$ & $3(10)$ \\
\hline Father asthma ever & $3(6)$ & $3(12)$ \\
\hline $\begin{array}{l}\text { Mother or father current } \\
\text { smoker }\end{array}$ & $19(27)$ & $8(28)$ \\
\hline \multicolumn{3}{|l|}{ Mother's education } \\
\hline Low & 7 (12) & $6(21)$ \\
\hline Moderate & $28(46)$ & $12(45)$ \\
\hline High & $25(42)$ & $10(34)$ \\
\hline \multicolumn{3}{|l|}{ Father's education } \\
\hline Low & $7(13)$ & $5(19)$ \\
\hline Moderate & $22(42)$ & $10(38)$ \\
\hline High & $24(45)$ & $11(41)$ \\
\hline
\end{tabular}

bronchoconstriction. Table 3 gives the results of the slopes and intercepts of the Borg and VAS scores. The intercept, which represents baseline perception, did not differ between the groups. Children with undiagnosed asthma were significantly less sensitive to signals of bronchoconstriction than children with diagnosed asthma, as illustrated by the slopes for Borg/ FEV1, which were twice as low in children with undiagnosed asthma compared with children with diagnosed asthma $(0.07$ and 0.14 , respectively; $\mathrm{p}=0.04)$. A similar trend was found for the VAS/FEV1 slope (0.06 and 0.11 , respectively; $\mathrm{p}=0.11$ ). Analysis of children not receiving inhaled steroids showed similar results for the slopes of Borg/FEV1 (0.07 and 0.16 for children with undiagnosed asthma and diagnosed asthma, respectively; $p=0.03)$. A significant result was found for the VAS/FEV1 slope (0.06 and 0.11 for children with undiagnosed asthma and diagnosed asthma, respectively; $\mathrm{p}=0.04$ ).

\section{DISCUSSION}

The present results show that children whose parents do not report a physician's diagnosis of asthma appear to perceive bronchoconstriction less well than children with diagnosed asthma. Baseline perception did not differ between both groups.

It was also found that, in real life, undiagnosed asthmatics are more frequent than those correctly diagnosed (8 versus $5 \%$ ). These results underline that underdiagnosis of asthma is still a problem and are in agreement with BRAUER et al. [17], who reported a similar result in a large cohort of children at the age of 4 yrs.

To the best of the current authors' knowledge, the present study is the first regarding the perception of dyspnoea in children whose parents do not report a physician's diagnosis of asthma. The current results are consistent with a previous study among Dutch adults [18], which showed that underpresentation of obstructive airway symptoms to the general practitioner is often caused by a decreased perception of dyspnoea. The results of VAS and Borg scores are identical, although analysis of the VAS slopes did not reach statistical significance. This can be explained by a better correlation of the Borg score with ventilation than the VAS score [14].

Children with undiagnosed asthma and a blunted sensation of dyspnoea are at increased risk for underestimation of their illness and a severe asthma attack [5]. Presumably, they will report fewer symptoms to their caregivers and physician. It has been suggested that the asthmatic inflammatory process could reduce perception of dyspnoea, possibly due to damage to the sensory receptors in the airways [16]. BOULET et al. [19] showed that adults with mild asthma not using anti-inflammatory agents perceive respiratory symptoms less acutely during metacholine-induced bronchoconstriction than those currently using anti-inflammatory agents. SALOME et al. [20] showed a better perception of dyspnoea in adults after treatment with inhaled corticosteroids. However, analysis of children not receiving inhaled corticosteroids showed the same results for the Borg/FEV1 slope as analysis of the whole group of children receiving or not receiving inhaled steroids. Furthermore, the results for the VAS slope showed a significantly lower perception in children with undiagnosed asthma. Therefore, the difference in perception of dyspnoea between the groups cannot be clarified by differences in the number of children using inhaled corticosteroids. Another explanation for the differences between children with undiagnosed and diagnosed asthma could be that children with undiagnosed asthma have an acquired degree of tolerance to bronchoconstriction due to adaptation related to frequent bronchoconstriction [21]. Furthermore, a low baseline FEV1 and severe bronchial responsiveness are associated with a low degree of perceptiveness for bronchoconstriction $[22,23]$. In the present study, however, differences in perception of bronchoconstriction between children with undiagnosed and diagnosed asthma could not be explained by differences in BHR or a lower FEV1. Future research should focus on possible methods of improving the perception and awareness of children with symptoms of asthma. The Borg scale has been used in children to measure the severity of perceived wheeze or chest tightness during induced airway narrowing [24]. Furthermore, perception indices are repeatable if asthma control remains unchanged [25]. In addition, NUIJSINK et al. [26] found a slope of 0.14 for the Borg/FEV1 correlation in 93 children aged (mean \pm SD) $10.9 \pm 2.6$ yrs with moderately severe diagnosed asthma (FEV1 $98 \pm 15 \%$ pred). The Borg slope in children with diagnosed asthma in the present study was in the same range as in the study by NUIJSINK et al. [26], which can be seen as a confirmation of the reliability of the method used. Furthermore, the bronchial hyperreactivity tests were performed by experienced lung function assistants, who also had experience with Borg and VAS scores in children. In adults (median age 25 yrs), VEEN et al. [27] found a slope of 0.06 for the Borg/FEV1 correlation in adults with brittle asthma and a Borg slope of 0.11 in stable asthma. Thus, the same small differences observed in the present study are found in adult patients with a clinically different asthma presentation.

Abnormal dyspnoea perception in children may be a factor in the delay in diagnosing asthma. Due to the cross-sectional 


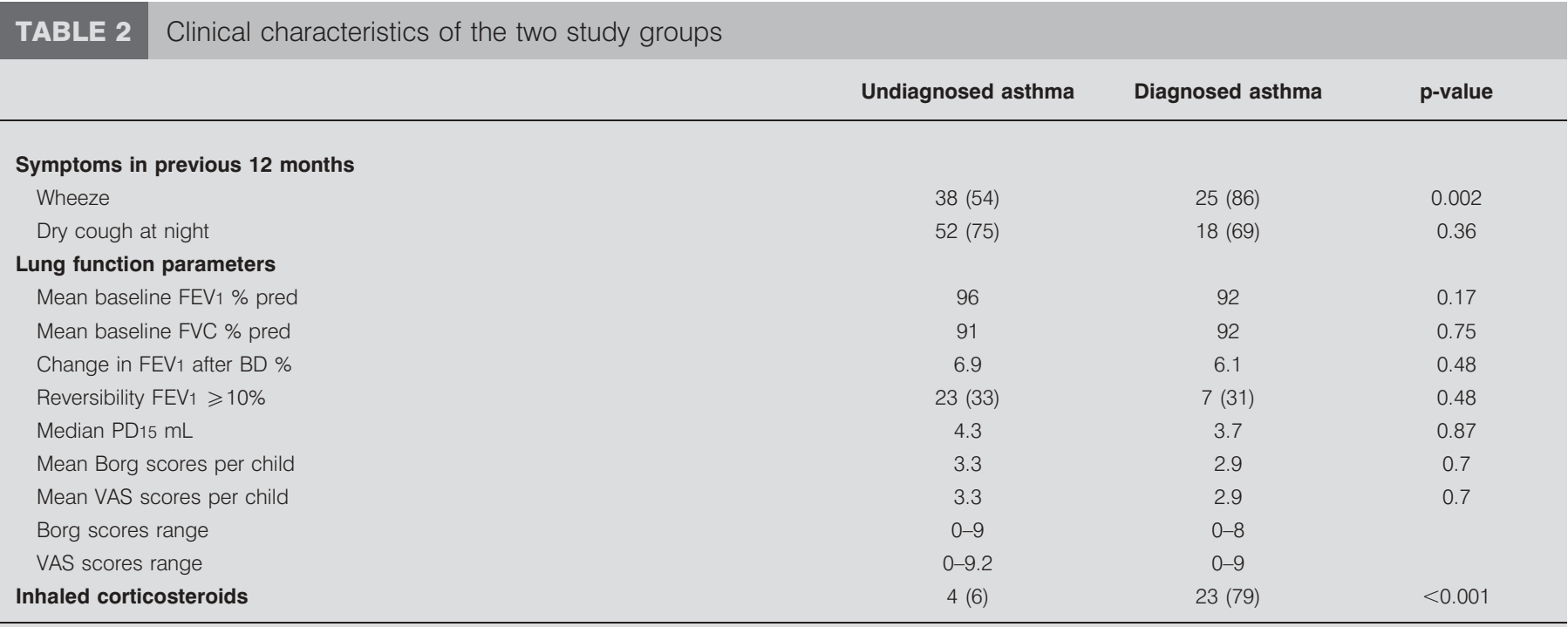

Data are presented as n (\%), unless otherwise stated. FEV1: forced expiratory volume in one second; \% pred: \% predicted; FVC: forced vital capacity; BD: bronchodilator; PD15: provocative dose of hypertonic saline causing a $15 \%$ fall in FEV1; VAS: visual analogue scale.

design of the present study, it is only possible to speculate about this. The child's poorer perception of dyspnoea might have contributed to the nondiagnosis, but there may be many other reasons to explain the fact that a medical label has not been attached. However, when children grow up they are much less under the direct attention of their parents. Subsequently, parents cannot take the child to the doctor if the children themselves did not notice and complain about their dyspnoea.

Some possible limitations should be mentioned. First, the ISAAC questionnaire used in the present study depended on the recall of asthma symptoms by parents. Recall by parents can be inaccurate. However, there is no reason to suppose that the inaccuracy influenced diagnosis differently in the different

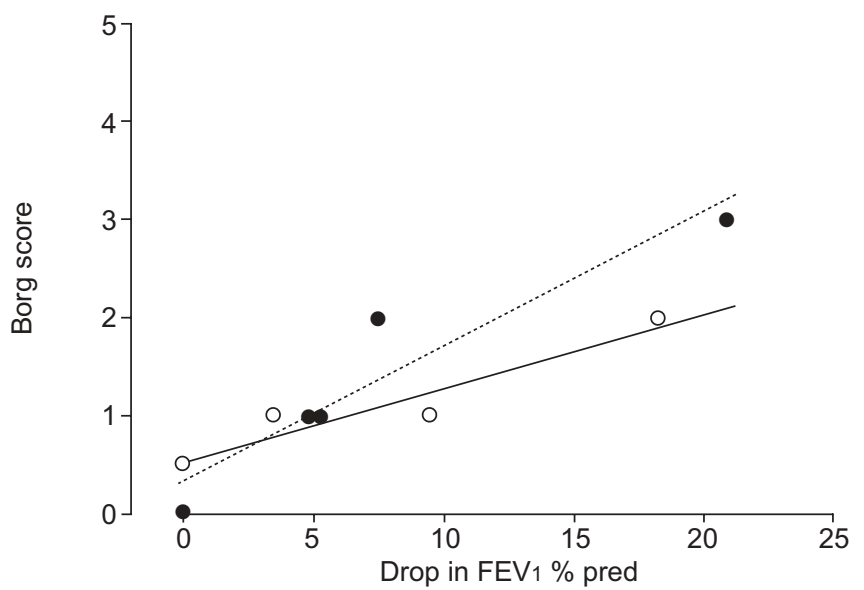

FIGURE 1. Representative example of the relationship between the Borg score and forced expiratory volume in one second $\left(\mathrm{FEV}_{1}\right)$. ........... linear regression of a child with diagnosed asthma $(\bullet)$; _ undiagnosed asthma $(\bigcirc)$. The correlation coefficient, slope and intercept are 0.89 , 0.14 and 0.34 for the child with diagnosed asthma and $0.93,0.07$ and 0.54 for the child with diagnosed asthma. \% pred: \% predicted. patient groups. Secondly, the results are only generalisable for children with undiagnosed asthma with a positive BHR. Thirdly, the challenge test does not reflect the real-life situation of bronchoconstriction episodes. Children will probably be more focused on their respiratory sensation during a provocation test in a laboratory setting than in daily life. Fourthly, the relatively rapid airway narrowing during induced bronchoconstriction probably makes it easier to assess the degree of bronchoconstriction [28]. Fifthly, the present study may have been biased due to selective nonparticipation. Information on the reasons for not participating in the study was not collected and thus the extent to which this may have biased the present results has not been analysed. It is possible that children with undiagnosed asthma more frequently refused to participate since they perceive fewer symptoms and, therefore, felt no urge to participate. These children could have poorer perception of dyspnoea than the participating children. Alternatively, it is possible that the participating children with undiagnosed asthma perceived more symptoms than the nonparticipating children and thus have a better perception of dyspnoea than

\begin{tabular}{lccc} 
TABLE 3 & $\begin{array}{l}\text { Intercepts and slopes of the Borg and visual } \\
\text { analogue scale (VAS) scores in children with } \\
\text { positive bronchial hyperresponsiveness }\end{array}$ \\
& Undiagnosed asthma Diagnosed asthma & p-value \\
\hline $\begin{array}{c}\text { Intercept } \\
\text { Borg }\end{array}$ & $0.65(-0.16-5.6)$ & $0.79(-0.57-5.1)$ & 0.43 \\
VAS & $0.96(-0.09-6.4)$ & $0.80(-0.05-5.1)$ & 0.99 \\
$\begin{array}{c}\text { Slope } \\
\text { Borg/FEV1 } \\
\text { VAS/FEV1 }\end{array}$ & $0.07(-0.09-0.40)$ & $0.14(-0.03-0.46)$ & 0.04 \\
\hline
\end{tabular}

Data are presented as median (range), unless otherwise stated. FEV1: forced expiratory volume in one second. 
nonparticipants. If both conditions happened, the perception of dyspnoea in real life is even worse than revealed in the present study.

The major strengths of the present study are that, to the current authors' knowledge, it is the first population-based study that evaluates perception of dyspnoea in children whose parents do not report a physician's diagnosis of asthma with the wellknown Borg scales. Furthermore, a clear definition of undiagnosed asthma was used involving the collection of objective measures.

In conclusion, children with bronchial hyperresponsiveness whose parents do not report a physician's diagnosis of asthma perceive their breathlessness less well during a provocation test than children with bronchial hyperresponsiveness and diagnosed asthma. For a number of children this might be an explanation for the delay in asthma diagnosis.

\section{REFERENCES}

1 Worldwide variations in the prevalence of asthma symptoms: the International Study of Asthma and Allergies in Childhood (ISAAC). Eur Respir J 1998; 12: 315-335.

2 Toelle BG, Marks GB. The ebb and flow of asthma. Thorax 2005; 60: 87-88.

3 Rubinfeld AR, Pain MC. Perception of asthma. Lancet 1976; 1: 882-884.

4 Peiffer C, Marsac J, Lockhart A. Chronobiological study of the relationship between dyspnoea and airway obstruction in symptomatic asthmatic subjects. Clin Sci (Lond) 1989; 77: 237-244.

5 Julius SM, Davenport KL, Davenport PW. Perception of intrinsic and extrinsic respiratory loads in children with life-threatening asthma. Pediatr Pulmonol 2002; 34: 425-433.

6 Boner AL, De Stefano G, Piacentini GL, et al. Perception of bronchoconstriction in chronic asthma. J Asthma 1992; 29: 323-330.

7 Yeatts K, Davis KJ, Sotir M, Herget C, Shy C. Who gets diagnosed with asthma? Frequent wheeze among adolescents with and without a diagnosis of asthma. Pediatrics 2003; 111: 1046-1054.

8 Joseph CL, Havstad S, Anderson EW, Brown R, Johnson CC, Clark NM. Effect of asthma intervention on children with undiagnosed asthma. J Pediatr 2005; 146: 96-104.

9 Chew FT, Goh DY, Lee BW. Under-recognition of childhood asthma in Singapore: evidence from a questionnaire survey. Ann Trop Paediatr 1999; 19: 83-91.

10 Quanjer PH, Tammeling GJ, Cotes JE, Pedersen OF, Peslin R, Yernault JC. Lung volumes and forced ventilatory flows. Report Working Party Standardisation of Lung Function Tests, European Community for Steel and Coal. Official Statement of the European Respiratory Society. Eur Respir J Suppl 1993; 16: 5-40.

11 Dales RE, Spitzer WO, Tousignant P, Schechter M, Suissa S. Clinical interpretation of airway response to a bronchodilator. Epidemiologic considerations. Am Rev Respir Dis 1988; 138: 317-320.

12 Weiland SK, Björkstén B, Brunekreef B, Cookson WO, von Mutius E, Strachan DP. Phase II of the International Study of Asthma and Allergies in Childhood (ISAAC II): rationale and methods. Eur Respir J 2004; 24: 406-412.
13 Sterk PJ, Fabbri LM, Quanjer PH, et al. Airway responsiveness. Standardised challenge testing with pharmacological, physical and sensitising stimuli in adults. Report Working Party Standardisation of Lung Function Tests, European Community for Steel and Coal. Official Statement of the European Respiratory Society. Eur Respir J Suppl 1993; 16: 53-83.

14 Wilson RC, Jones PW. A comparison of the visual analogue scale and modified Borg scale for the measurement of dyspnoea during exercise. Clin Sci (Lond) 1989; 76: 277-282.

15 Asher MI, Keil U, Anderson HR, et al. International Study of Asthma and Allergies in Childhood (ISAAC): rationale and methods. Eur Respir J 1995; 8: 483-491.

16 Roisman GL, Peiffer C, Lacronique JG, Le Cae A, Dusser DJ. Perception of bronchial obstruction in asthmatic patients. Relationship with bronchial eosinophilic inflammation and epithelial damage and effect of corticosteroid treatment. J Clin Invest 1995; 96: 12-21.

17 Brauer M, Hoek G, Smit HA, et al. Air pollution and development of asthma, allergy and infections in a birth cohort. Eur Respir J 2007; 29: 879-888.

18 van Schayck CP, van der Heijden FM, van den Boom G, Tirimanna PR, van Herwaarden CL. Underdiagnosis of asthma: is the doctor or the patient to blame? The DIMCA project. Thorax 2000; 55: 562-565.

19 Boulet LP, Turcotte H, Cartier A, et al. Influence of beclomethasone and salmeterol on the perception of methacholineinduced bronchoconstriction. Chest 1998; 114: 373-379.

20 Salome CM, Leuppi JD, Freed R, Marks GB. Perception of airway narrowing during reduction of inhaled corticosteroids and asthma exacerbation. Thorax 2003; 58: 1042-1047.

21 Burdon JG, Juniper EF, Killian KJ, Hargreave FE, Campbell EJ. The perception of breathlessness in asthma. Am Rev Respir Dis 1982; 126: 825-828.

22 Bijl-Hofland ID, Cloosterman SG, Folgering HT, Akkermans RP, van Schayck CP. Relation of the perception of airway obstruction to the severity of asthma. Thorax 1999; 54: 15-19.

23 Koh YI, Choi IS, Lim H. Airway responsiveness as a direct factor contributing to the dyspnoea perception in asthma. Respir Med 2001; 95: 464-470.

24 Baker RR, Mishoe SC, Zaitoun FH, Arant CB, Lucas J, Rupp NT. Poor perception of airway obstruction in children with asthma. J Asthma 2000; 37: 613-624.

25 Salome CM, Reddel HK, Ware SI, et al. Effect of budesonide on the perception of induced airway narrowing in subjects with asthma. Am J Respir Crit Care Med 2002; 165: 15-21.

26 Nuijsink M, Hop WC, Jongste JD, Sterk PJ, Duiverman EJ. Perception of bronchoconstriction is associated with the severity of asthma in children. Eur Respir J 2005; 26: Suppl. 49, 478s.

27 Veen JC, Smits HH, Ravensberg AJ, Hiemstra PS, Sterk PJ, Bel EH. Impaired perception of dyspnea in patients with severe asthma. Relation to sputum eosinophils. Am J Respir Crit Care Med 1998; 158: 1134-1141.

28 Boudreau D, Styhler A, Gray-Donald K, Martin JG. A comparison of breathlessness during spontaneous asthma and histamine-induced bronchoconstriction. Clin Invest Med 1995; 18: 25-32. 